\section{Broad Institute keeps CRISPR tools open}

As chief communications officer at the Broad Institute of MIT and Harvard, I wish to clarify that the institute makes patent rights for CRISPR-Cas9 genome-editing technologies available globally across academia and industry (see J. Sherkow Nature 532, 172-173; 2016).

For academic research, the patent rights are freely available and we openly share CRISPR reagents through the non-profit repository Addgene. So far, Addgene has processed more than 30,000 requests for these reagents.

For commercial research, we designed a non-exclusive licensing model. For commercial products, we also follow a non-exclusive model - except for human therapeutics, for which we use an 'inclusive innovation model'. This is because companies often need exclusivity to justify investing in expensive clinical trials.

The CRISPR-Cas9 licensing agreement with our primary licensee, Editas, stipulates that, for target genes not being pursued by Editas, we (Broad, Harvard and MIT) will make the licences available to other parties to develop new medicines. This helps to ensure that no promising target genes will be neglected. Lee McGuire Broad Institute of MIT and Harvard, Cambridge, Massachusetts, USA. lmcguire@broadinstitute.org

\section{Revive China's green GDP programme}

In a potentially big step towards achieving its target of sustainable growth by 2020 , China's government is developing a green measure of gross domestic product (GDP). We suggest that the country's upcoming audit of its natural-resource assets would provide an ideal opportunity to launch this 'green GDP', which factors the environmental costs of economic growth into the conventional GDP.

The government is recognizing that economic growth comes at too high a price. The cost of China's pollution damage roughly quadrupled from 2004-13, and has accounted for up to $3 \%$ of annual GDP over the past decade. Each year, there are 350,000 to 500,000 premature deaths from particulates in cities (Z. Chen et al. Lancet 382, 1959-1960; 2013). Indeed, the health cost of air pollution amounts to onethird of total environmental costs.

Although China's original green GDP programme of 2006 was shelved within a year, studies on a green GDP index have never stopped. In the push for green development, faster economic growth is no longer the priority. And under China's latest FiveYear Plan (see Nature 531, 425-426; 2016), local governments are now accountable for environmental quality and ecological conservation.

Jinnan Wang ${ }^{\star}$ Chinese Academy for Environmental Planning, Beijing, China.

wangjn@caep.org.cn

${ }^{*}$ On behalf of 7 correspondents (see go.nature.com/rsebg 9 for full list).

\section{Bee-hawking hornet already in line of fire}

We agree with Frederico Santarém and colleagues that public campaigns will help to control the invasive Asian hornet Vespa velutina (see Nature 532, 177; 2016). However, this bee-hawking hornet has been on Europe's risk-assessment list for invasive alien species and targeted for action since June 2015 (see go.nature.com/gigftz). It has also been intensively researched since 2008 under the European Agricultural Guarantee Fund's apiculture programme.

The only way found so far to contain the $V$. velutina invasion is to destroy colonies as soon as nests are spotted (see J. R. Beggs et al. BioControl 56, 505-526; 2011). Public awareness and collaboration are crucial to help detect these nests in tree crowns.

The hornet's real threat is to pollinators, not to humans (see, for example, C. Villemant et al. Biol. Conserv. 144, 2142-2150; 2011). EU legislation aims to coordinate a plan for invasion control, which also depends on a greater willingness among European researchers to work together.

Quentin Rome, Claire Villemant Institut de Systématique, Évolution, Biodiversité (ISYEB), UMR 7205 - CNRS, MNHN, UPMC, EPHE, Sorbonne Universités, Paris, France. rome@mnhn.fr

\section{Industry parks limit circular economy}

We suggest that China's proposed circular economy should cover the entire life cycle of products and not just focus on industrial parks (see J. A. Mathews and H. Tan Nature 531, 440-442; 2016).

Consumer-waste recycling, for example, should also be part of the circular economy. The delivery of online orders in China last year accounted for some 8 billion plastic bags, 10 billion boxes and 17 billion metres of adhesive tape, yet most of the retailers and companies responsible have no recycling arrangements (see go.nature. com/pv2omq; in Chinese).

Industrial parks designed for a circular economy can have serious limitations, because the interdependence of manufacturers creates a vulnerability. For example, if any one of them closes down or switches to other products, the whole production chain can collapse.

Moreover, these parks cannot be built everywhere. Site selection depends on local manufacturing priorities and on that area's environmental, social and technological conditions. Transforming conventional industrial parks and zones to circular-economy parks has also been problematic because of poor planning, design and supervision.

Government-controlled circular-economy projects need to be made publicly accountable to safeguard against financial corruption and to ensure transparent oversight. Disorderly operation, enforcement or supervision in the recycling of pollutants or hazardous materials, for example, can lead to disasters such as last year's huge chemical explosion at Tianjin (see Z. Tang et al. Nature 525, 455; 2015).

Xin Miao Harbin Institute of Technology, Harbin, China.

Yanhong Tang Northeast Agricultural University, Harbin, China. xin.miao@aliyun.com

\section{Ukraine should cut back nuclear power}

Thirty years on from the Chernobyl nuclear disaster, the Ukrainian government has increased the contribution of nuclear power to the nation's total energy balance. In 1991, it was $8 \%$; by 2014 , it had risen to $22 \%$ (go.nature.com/s4qgjk).

In my view, Ukraine should be following Lithuania's lead. Lithuania has ceased to depend on nuclear power, substituting renewable energy sources (mostly biofuels) for its former $26 \%$ nuclear-power contribution in 1991. Renewables are likewise thriving in Latvia (39\%) and Estonia (27\%) (go.nature.com/ z3ibww); Georgia (31\%; go.nature. com/5ihqsg); and Kyrgyzstan (28\%; go.nature.com/slcnsw).

Ukraine lags way behind because of the funding deficit for new green technologies, with renewables accounting for just $2.6 \%$. This is despite the country's favourable conditions for green energy, including wind, solar and hydropower. This untapped potential could be swiftly realized with appropriate financial and legislative support.

Alexander Gorobets Sevastopol, Crimea.

alex-gorobets@mail.ru 